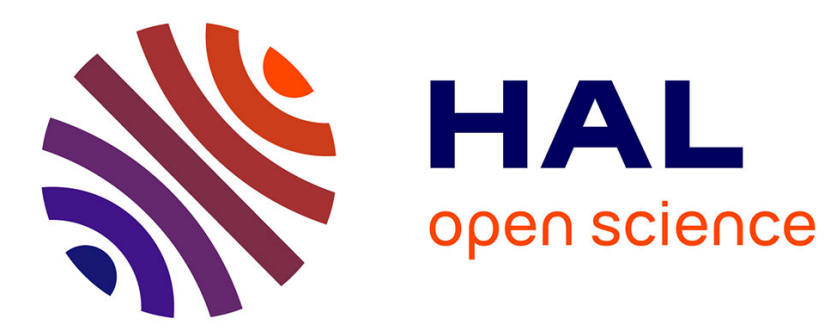

\title{
Glass formation and properties of Ge-Ga-Te-ZnI2 far infrared chalcohalide glasses
}

Huijuan Xu, Xunsi Wang, Qiuhua Nie, Yuju He, Peiquan Zhang, Tiefeng Xu, Shixun Dai, Xianghua Zhang

\section{- To cite this version:}

Huijuan Xu, Xunsi Wang, Qiuhua Nie, Yuju He, Peiquan Zhang, et al.. Glass formation and properties of Ge-Ga-Te-ZnI2 far infrared chalcohalide glasses. Journal of Non-Crystalline Solids, 2014, 383, pp.212-215. 10.1016/j.jnoncrysol.2013.05.002 . hal-00859813

\section{HAL Id: hal-00859813 https://hal.science/hal-00859813}

Submitted on 8 Jan 2014

HAL is a multi-disciplinary open access archive for the deposit and dissemination of scientific research documents, whether they are published or not. The documents may come from teaching and research institutions in France or abroad, or from public or private research centers.
L'archive ouverte pluridisciplinaire HAL, est destinée au dépôt et à la diffusion de documents scientifiques de niveau recherche, publiés ou non, émanant des établissements d'enseignement et de recherche français ou étrangers, des laboratoires publics ou privés. 


\title{
Glass formation and properties of Ge-Ga-Te-ZnI $\mathbf{I}_{2}$ far infrared chalcohalide glasses
}

\author{
Huijuan Xu ${ }^{1}$, Xunsi Wang ${ }^{1 *}$, Qiuhua Nie ${ }^{1}$, Yuju He ${ }^{1}$, Peiquan Zhang ${ }^{1}$, Tiefeng \\ $\mathrm{Xu}^{1}$, Shixun Dai ${ }^{1}$ and Xianghua Zhang ${ }^{2}$
}

1. Laboratory of Infrared Material and Devices, Ningbo University, 315211, Ningbo,

\section{China}

2. Laboratoire des Verres et ceramiques, Universite de Rennes I, 35042 Rennes

\author{
Cedex, France
}

\begin{abstract}
In order to develop novel far infrared window material, a series of Ge-Ga-Te-ZnI 2 chalcohalide glasses were prepared by traditional melt-quenching method and its glass-forming region was determined also. Here, some measurements including X-Ray Diffraction (XRD), differential thermal analysis (DTA), UV-Vis-NIR absorption spectrum, and Infrared optical transmission spectra were carried out. The allowed indirect transition optical band gap was calculated according to the classical Tauc equation. The results show that with the addition of $\mathrm{ZnI}_{2}$, the glass-forming ability and thermal stability are improved gradually. With the contents of $\mathrm{ZnI}_{2}$ increased from 5 to 20 at $\%$, continued blue-shifting occurs in the cutting-off absorption edge of short-wavelength and the values of indirect optical band gaps were observed with ranges from 0.596 to $0.626 \mathrm{eV}$ in these glasses. These

\footnotetext{
*Corresponding author.Tel:13586839255

E-mail address: xunsiwang@siom.ac.an (X.Wang).
} 
$\mathrm{GeTe}_{4.3}-\mathrm{GaTe}_{3}-\mathrm{ZnI}_{2}$ glasses show wide optical transmission and the infrared cut-off wavelengths are larger than $25 \mu \mathrm{m}$, which implies that the Ge-Ga-Te-ZnI chalcogenide glasses possess the potential of far-IR optical window applications.

Keywords: Chalcogenide glass; Far-infrared; Te-based

\section{Introduction}

In recent decades, tremendous interest has been focused on the exploration of out-space. The European Space Agency (ESA) Darwin mission aims to detect life signals in these explants with directly analyzing extra solar earth-like planets [1]. The main biological markers of life are the molecules of water, ozone and carbon dioxide which have their infrared signatures in the 6,10 and $15 \mu \mathrm{m}$ regions and development of IR optics operating in the $4-20 \mu \mathrm{m}$ regions is critical for space exploration [2]. Chalcogenide glasses are well known for their transparency in the infrared optical range and their ability to be drawn into fiber. Such optical fibers can transmit light wavelength ranging from 2 to $20 \mu \mathrm{m}$, depending on the fiber glass compositions [3]. The transparency of a chalcogen based glass in the infrared region is determined by the multi-phonon absorption and it correlated to the chalcogen atomic weight, bond energy and so on [4]. For instance, the IR edge for the $\mathrm{S}$ based glasses is limited to $12 \mu \mathrm{m}$ (bulk glass)while for a Se based materials the edge is shifted towards $16 \mu \mathrm{m}$ [5]. To extend the transparency towards longer wavelength it is necessary to use Te, the heaviest chalcogen $[6,7]$. However, there are still some problems for Te-based glasses preparation: first, tellurium has strong metallic character in comparison with $\mathrm{S}$, Se, its glass-forming ability is relatively weak; second, the glass transition 
temperature of Te-based chalcogenide glasses is low and thermal stability is poor; third, due to structure defects, traditional Te-based glasses are synthesized with Se or As, which will make infrared optical wavelength $(<16 \mu \mathrm{m})$ far less than the theoretical level $(20 \mu \mathrm{m})$ or environment-hazardous. In a word, the development of Te-based glasses is restricted by all these defects, so some basic elements of glass former or adjuster, such as Ga, Ge, I or others are needed.

Up to now, some advances of the Te based glasses and the applications in far-Infrared region have been reported. In the early stage, Tichy et al. [8] reported that the transparent range of Se-Te-I glasses could be extended from 2 to $21 \mu \mathrm{m}$ and these glasses could be attractive for further studies in connection with their possible applications in $\mathrm{CO}_{2}$ lasers. Bureau and Danto [5] have reported the glass forming region in the Te-Ga-Ge ternary diagram, within which the most promising glass composition is $\mathrm{Te}_{75} \mathrm{Ga}_{10} \mathrm{Ge}_{15}$. The IR transmitting range of $\mathrm{Te}_{75} \mathrm{Ga}_{10} \mathrm{Ge}_{15}$ glass sample was from 2 to $25 \mu \mathrm{m}$, while there is an obvious absorption around $15-20 \mu \mathrm{m}$ band aroused by some impurities, and it is very difficult to be removed by ordinary purification processes. Recently, Lucas et al. [2] reported that Ge-Te-I system could form relatively stable glasses and exhibited good transmitting property in the range of $2-22 \mu \mathrm{m}$, but it does not resolve the volatilization problem of $\mathrm{I}_{2}$ in evacuating process. However, it reveals that some halogen contained compound (such as heavy metal halides) may be a new candidate to improve Ge-Te-based chalcogenide glasses and to advance the chalcogenide glass for the application of infrared thermal imaging and bio-sensing. X. Wang et al. and G. Wang et al have make some attempts to add metal 
halide into the Te-based chalcogenide glasses and got some interesting results, such as glasses in Ge-Te-AgI [9] and Ge-Te-ZnI 2 [10] systems, but there are still need to develop more new Te-based chalcohalide glass systems and improve the glass stability.

In the present work, with heavy metal halide $\mathrm{ZnI}_{2}$ acting as glass modifier in the network of Ge-Ga-Te glass, a new pseudo-quaternary glass forming region was determined. With the help of DTA, UV-Vis-NIR absorption and FTIR optical spectra testing to the glass system, optical effects of alkali halide $\mathrm{ZnI}_{2}$ on the Ge-Ga-Te glasses were discussed systematically and the alkali halide show much help to improve the stability against crystallization of Te-based chalcogenide glass. The present study will help to develop perfect optical materials suitable for optical applications in far-infrared spectral range.

\section{Experimental}

A systematic series of $\mathrm{Ge}-\mathrm{Ga}-\mathrm{Te}-\mathrm{ZnI}_{2}$ glasses were prepared by traditional melt-quenching method. Elemental raw materials of high purity Ge (99.999\%), Te (99.999\%), Ga (99.999\%), and $\mathrm{ZnI}_{2}(99.9 \%)$ were carefully weighed and transferred into quartz ampoules, which were then sealed under vacuum at a pressure of $2 \times 10^{-3} \mathrm{~Pa}$. The quartz ampoules containing the raw materials were heated at $850^{\circ} \mathrm{C}$ for $15 \mathrm{~h}$ in rocking furnaces to ensure the mixture's homogenization. Then, the ampoules were quenched in water at room temperature, swiftly moved to a preheated furnace to anneal at the temperature, below $10^{\circ} \mathrm{C}$ of $\mathrm{T}_{\mathrm{g}}$ for $5 \mathrm{~h}$ to minimize inner tension induced by a quenching step. After that, glass rods were obtained by taking them out from the 
ampoules and finally cut into disks of about $1.5 \mathrm{~mm}$ thickness which were then polished for testing [10].

Densities were measured according to the Archimedes principle and the accuracy was $0.001 \mathrm{~g} / \mathrm{cm}^{3}$.All optical tests were carried out at room temperature. To identify the amorphous nature, X-ray diffraction (XRD) analysis was carried out with a powder diffractometer (BRUKER AXS GMBH) using $\mathrm{CuK} \alpha$ radiation $(36 \mathrm{kV}, 20 \mathrm{~mA})$. Differential thermal analysis (DTA) measurement was carried out in the temperature range $100-350^{\circ} \mathrm{C}$ at a heating speed of $10^{\circ} \mathrm{C} / \mathrm{min}$ by a CRY-2 thermal analyzer for sample weights of approximately $15 \mathrm{mg}$. The visible absorption spectra of glass samples were recorded in the range of 1600-2500nm using a Perkin-Elmer Lambda 950 UV-Vis-NIR spectrophotometer. The IR transmission spectra of samples were obtained in the range of $4000-400 \mathrm{~cm}^{-1}$ using Nicolet 380 Fourier Infrared spectrophotometer.

\section{Results and discussion}

\subsection{Glass-forming region}

The glass-forming region of Ge-Ga-Te- $\mathrm{ZnI}_{2}$, a pseudo-quaternary system is obtained by quenching $8 \mathrm{~g}$ melts in water and shown in Fig.1. The investigated compositions in this system include Series A: $\left(\mathrm{GeTe}_{4.3}\right)_{60}\left(\mathrm{GaTe}_{3}\right)_{40-\mathrm{x}}\left(\mathrm{ZnI}_{2}\right)_{\mathrm{x}}$ $(\mathrm{x}=0,5,10,15 \mathrm{~mol} \%)$, Series B: $\left(\mathrm{GeTe}_{4.3}\right)_{65+\mathrm{x}}\left(\mathrm{GaTe}_{3}\right)_{30-\mathrm{x}}\left(\mathrm{ZnI}_{2}\right)_{5+\mathrm{x}}(\mathrm{x}=0,5,10,15 \mathrm{~mol} \%)$, Series C: $\left(\mathrm{GaTe}_{3}\right)_{5}\left(\mathrm{GeTe}_{4.3}\right)_{95-\mathrm{x}}\left(\mathrm{ZnI}_{2}\right)_{\mathrm{x}}(\mathrm{x}=0,5,10,15,20 \mathrm{~mol} \%)$. It presents a detailed distribution of glass-forming region about Ge-Ga-Te-ZnI 2 . According to the three series, two main trends were observed, firstly the addition of I in the network appears 
to help stabilizing the glass and acting as a non-bridging modifier; secondly, in the first series, an addition of $\mathrm{ZnI}_{2}$ in concentrations higher than $10 \%$ will lead to a rapid crystallization.

\subsection{X-ray diffraction investigations}

Fig. 2 presents the XRD patterns of sample glasses: $\left(\mathrm{GaTe}_{3}\right)_{5}-\left(\mathrm{GeTe}_{4.3}\right)_{95-\mathrm{x}}-\left(\mathrm{ZnI}_{2}\right)$ ${ }_{x}(x=5,10,15,20 \mathrm{~mol} \%)$ and the samples are identified as $T_{0}, T_{1}, T_{2}$ and $T_{3}$. The results of X-ray diffraction investigation show that the glass samples under study keep amorphous states as it is shown in Fig. 2. The addition of $\mathrm{ZnI}_{2}$ up to $20 \mathrm{~mol} \%$ does not introduce any sharp peak. As there are no obvious crystalline phases appeared in the measured spectra by X-ray diffraction investigation, the amorphous nature of the synthesized glasses could be confirmed [11].

\subsection{Physical properties}

Table 1 lists the components and physical properties of the $T_{0}, T_{1}, T_{2}$, and $T_{3}$ samples. The density $(\rho)$ increased with the $\mathrm{ZnI}_{2}$ content increasing, as the molar volume $\left(V_{\mathrm{m}}\right)$ decreased. The density is determined by the mean atom molar mass and packing efficiency in atoms. With the increasing of content $\mathrm{ZnI}_{2}$, the values of glass density increased accordingly, because of that $\mathrm{ZnI}_{2}$ (larger atomic weight of 319) has a large polarization rate. That will also lead to the decrease of average molar volume; and then bring about the packing density and ratios of the glasses structure being promoted, in other words, the glass density increased linearly with the content of $\mathrm{ZnI}_{2}$..

The molar volume of a given composition is calculated using the following 
formula [12]:

$$
V_{m}=\frac{\sum_{i} M_{i}}{\rho}
$$

where $M_{i}$ denotes the molar mass of the glass, $M_{i}=A_{i} B_{i}, \quad\left(A_{i}\right.$ : the molar concentration,

$B_{i}$ : the molecular weight of the component).

\subsection{Thermal properties}

Fig. 3 shows the DTA curves for the glass samples, Table 1 lists the results of the DTA measurement. Here, the glass transition temperature $\left(\mathrm{T}_{\mathrm{g}}\right)$ and onset crystallization temperature $\left(\mathrm{T}_{\mathrm{x}}\right)$ were measured for the samples. The common stability criterion of $\Delta \mathrm{T}=\mathrm{T}_{\mathrm{x}}-\mathrm{T}_{\mathrm{g}}$ is used to evaluate the thermal stability of these glasses [13]. As shown in Table 1, the $\mathrm{Tg}$ values stay nearly constant (150-152 ${ }^{\circ} \mathrm{C}$ ), but little difference with $\mathrm{Znl}_{2}$ concentration increasing, just as that first increase from 150 to 152 and then decrease to $151^{\circ} \mathrm{C}$. This can probably be ascribed to that the iodine atom can form covalent bonds with tellurium by trapping the metallic electrons and decreasing the tendency to formation of tellurium microcrystals [9, 14]. So the connectivity of glass network is improved and glass forming ability is enhanced consequently. Then, with too much $\mathrm{ZnI}_{2}$ co-doped, the $\mathrm{T}_{\mathrm{g}}$ decreased, as that can be ascribed to the decreasing of glass network connectivity with excessive halogens introduced to break off much glass network structure of short-range order.[15]. In all, the values of $\mathrm{T}_{\mathrm{g}}$ first increase and then decrease with the addition of $\mathrm{ZnI}_{2}$.

\subsection{Analysis of near infrared absorption spectra and optical band gap}

The Vis-NIR absorption and transmission spectra of the glass samples were shown in Fig. 4. In short wavelength absorption areas, the optical cut-off edges of electric absorption appear blue shifts obviously with the increasing of the $\mathrm{ZnI}_{2}$ contents. This can be ascribed to that the addition of I with higher electronegativity in the glass network leads to enlargement of the width of the forbidden band [16]. Besides, the $\mathrm{Zn}^{2+}$ cation compensates the negative charge of Te-non-bridging atoms [10]. It is clearly demonstrated that this phenomenon generates a blue-shift of the short-wavelength cut-off edge. So it reduces the delocalization of the electrons in the 
glass.

The absorption coefficient is given by the following quadratic equation, which is often called the Tauc law[17]:

$$
\alpha(\omega) \cdot h \omega=B\left(h \omega-\mathrm{E}_{\mathrm{opt}}\right)^{m}
$$

Where $E_{\mathrm{opt}}$ is the Tauc optical band gap, $\alpha$ is the absorption coefficient determined as $\alpha=2.303 A / \mathrm{d}$ ( $A$ - optical density, $d-$ thickness of the samples), $\mathrm{h}$ is plank constant, $\omega$ is the incident light angular frequency and $m$ is a parameter depending on the transition type of the absorption edge. The $m$ is equal to $1 / 2$ and 2 for direct allowed and indirect allowed transition. $B$ is a constant that depends on the electronic transition probability, which is expressed as:

$$
B=\frac{(4 \pi / c) \sigma_{0}}{n_{0} \Delta E}
$$

Where $\Delta E$ is the located-state tail width and $\sigma_{0}$ the minimum metallic conductivity.

Fig. 5 shows the indirect allowed band gap of the four glass samples. The relationship between optical gap and content of heavy metal halide is illustrated in the inserted upper left figures. By extrapolating the linear portion of the curves to zero value of absorption, the value of the indirect optical band gap of the $\mathrm{Ge}-\mathrm{Ga}-\mathrm{Te}-\mathrm{ZnI} \mathrm{I}_{2}$ glass system is determined, as show in Table 1. The obtained value of $E_{\text {opt }}$ revealed that the indirect optical gap increased with the $\mathrm{ZnI}_{2}$ content increasing. That may be explained as the increase of the average bond energies of the system. Pauling proposed that single covalent bond energy of heteronuclear bonds D (A-B) are calculated using the following formula [18]:

$$
D(A-B)=[D(A-A) * D(B-B)]^{0.5}+30\left(\chi_{A}-\chi_{B}\right)^{2}
$$


Where $\chi_{A}$ and $\chi_{B}$ are the electronegativities of the atoms $\mathrm{A}$ and $\mathrm{B}, \mathrm{D}(\mathrm{A}-\mathrm{A})$ and $\mathrm{D}$ (B-B) are the bond energies of $\mathrm{A}-\mathrm{A}$ and $\mathrm{B}-\mathrm{B}$ bonds, respectively. The values of chemical bond energies are show in Table 1.

In Ge-Ga-Te-ZnI 2 glass system, $\mathrm{ZnI}_{2}$ enters into the Ge-Ga-Te glass network and forms the $\mathrm{Zn}-\mathrm{Te}$ and Te-I bonds, which thus lead to the decreasing of the concentration of Te-Te bonds [19]. Since the bond energy of Zn-Te $(155.2 \mathrm{~kJ} / \mathrm{mol})$ and Te-I $(148.1 \mathrm{~kJ} / \mathrm{mol})$ are higher than that of Te-Te bonds $(142.3 \mathrm{~kJ} / \mathrm{mol})$, the average bond energy of the system increases, which results in the increase of the optical band gap.

\subsection{IR transmission spectra}

As shown in Fig. 6, the most fascinating and original feature of these novel glasses is their ultra wide transparency window. The transmission of the studied glass samples extends to far IR (cut-off edge beyond $25 \mu \mathrm{m}$ ) and shows stable to $\mathrm{ZnI}_{2}$ co-doping. The quick drop in transmittance between 20 and $25 \mu \mathrm{m}$ sourced from the functions of hybrid multi-phonons, which can be divided into two or more order of the fundamental phonon mode or lateral optical mode coupling [20]. With increasing of the $\mathrm{ZnI}_{2}$ content transmission of the studied glass samples decreases, which could be explained as follows. The metal halide $\mathrm{ZnI}_{2}$ with high polarization rate can enter into the glass network, which will lead to increasing the refractive index [21] and emission cross-section. Some absorption bands in IR region are shown in Fig. 6. The strong absorption peak is located at $13 \mu \mathrm{m}$, which can be ascribed to the $\mathrm{Ge}-\mathrm{O}$ covalent bonds vibration[22]. The heavy metal halide $\mathrm{ZnI}_{2}$ is easy to deliquescence 
and introduces the impurities such as $\mathrm{H}_{2} \mathrm{O}$. As the content of $\mathrm{ZnI}_{2}$ increases, the $\mathrm{Ge}-\mathrm{O}$ absorption band is gradually strengthened. An absorption peak is observed near $15 \mu \mathrm{m}$, which might be attributed to harmonic intrinsic vibrations of Ga-containing structural units[23]. Thus, in order to reduce the impurity content, the glass purification process should be considered.

\section{Conclusions}

This study reports on the synthesis of Ge-Te-Ga-ZnI 2 bulk optical glasses. The introduction of heavy metal halide makes the glasses much easier to prepare and more stable against crystallization. X-ray diffraction investigations reveal the amorphous nature of the synthesized glass samples. With the increasing of $\mathrm{ZnI}_{2}$ content, the density of the glasses increases while the molar volume of the glasses decreases. Meanwhile, the $\mathrm{Zn}-\mathrm{Te}$ and Te-I bonds are formed, and that will decrease the concentration of Te-Te bonds, and increase the band gap instead. The present Te-based glasses have a wide optical transparency window ranging from 1.9 to $25 \mu \mathrm{m}$ and therefore will enable the development of a new generation of infrared systems.

\section{Acknowledgments}

This work was financially supported by the Natural Science Foundation of China (Grant Nos. 60878042, 61111130197,60908032, 61177087 and 60978058), Scientific Research Fund of Zhejiang Provincial Education Department (20070964, R1101263), Natural Science Foundation of Ningbo (Grant No. 2010A610171), Teaching and Research Award Program for Outstanding Young Teachers in Higher Education Institutions of MOE, P.R.C. Ningbo optoelectronic materials and devices creative 
team (2009B21007), Scientific Research Foundation of Graduate School of Ningbo

University and sponsored by K. C. Wong Magna Fund in Ningbo University.

\section{References}

[1] Guoxiang Wang, Qiuhua Nie, Xunsi Wang, Xiang Shen, Fen Chen, Tiefeng Xu, Shixun Dai, Xianghua Zhang, J. Appl. Phys. 110 (2011) 043536-043540.

[2] A. A. Wilhelm, C. Boussard-Plédel, Q. Coulombier, J. Lucas, B. Bureau, P. Lucas, Adv. Mater. 19 (2007) 3796-3800.

[3] S. Maurugeon, B. Bureau, C. Boussard-Plédel, A. J. Faber, X. H. Zhang, W. Geliesen, J. Lucas, J.Non-Cryst. Solids 355 (2009) 2074-2078.

[4] S. M. El-sayed, H. M. Saad, G. A. Amin, F. M. Hafez, M. Abd-El-Rahman, J. Phys. Chem. Solids 68 (2007) 1040-1045.

[5] S. Danto, P. Houizot, C. Boussard-Pledel, X. H. Zhang, F. Smektala, J. Lucas, Adv. Funct. Mater. 16 (2006) 1847-1852.

[6] Z. Yang, P. Lucas, J. Am. Ceram. Soc. 92 (2009) 2920-2923.

[7] S. Maurugeon, C. Boussard-Plédel, J. Troles, A. J. Faber, P. Lucas, X. H. Zhang, J. Lucas, B. Bureau, J. Lightw. Tehnol. 28 (2010) 3358-3363.

[8] L. Tichý, V. Smrčka, H. Tichá, P.Tomiška, J. Mater. Sci. Lett. 9 (1990) 681-685.

[9] Xunsi Wang, Qiuhua Nie, Guoxiang Wang, Jie Sun, Baoan Song, Shixun Dai, Xianghua Zhang, Bruno Bureau, Catherine Boussard, Clément Conseil, Hongli Ma, Spectrochim. Acta, Part A 86 (2012) 586-589.

[10] Qiuhua Nie, Guoxiang Wang, Xunsi Wang, Mohamed Barj, Tiefeng Xu, Shixun Dai, Jong Heo, J.Non-Cryst. Solids 357 (2011) 2362-2365.

[11] Rashmi , U. Dhawan, Powder Diffr. 17 (2002) 41-43.

[12] F. El-Diasty, F. A. Abdel Wahab, M.Abdel-Baki, J. Appl. Phys. 100 (2006) 093511-093517.

[13] Z. Yang, G. Tang, L. Luo, W. Chen, J. Am. Ceram. Soc. 90 (2007) 667-669.

[14] M. A. Afifi, N. A.Hegab, H. E. Atyia, A. S.Farid, J. Alloys Compd. 463 (2008) 10-17.

[15] Qiuhua Nie, Guoxiang Wang, Xunsi Wang, Shixun Dai, Shengwei Deng, Tiefeng Xu, Xiang Shen, Opt. Commun. 283 (2010) 4004-4007.

[16] Pál Jóvári, Ivan Kaban, Bruno Bureau, Allison Wilhelm, Pierre Lucas, Brigitte Beuneu, Dariusz A Zajac, J. Phys.: Condens. Matter 22 (2010) 404207-404215.

[17] J. Tauc, Amorphous and liquid semiconductors, Plenum Press, 1974

[18] L. Pauling, The Nature of Chemical Bonds, third ed.Cornell University, 1960

[19] K. Ramesh, S. Asokan, K. S. Sangunni, E. S. R. Gopal, J. Phys. Chem. Solids 61 (2000) 95-101.

[20] Qiuhua Nie, Guoxiang Wang, Xunsi Wang, Shixun Dai, Shengwei Deng, Tiefeng Xu, Xiang Shen, Mater. Res. Bull. 45 (2010) 1141-1144.

[21] Shixun Dai, Guoxiang Wang, Qiuhua Nie, Xunsi Wang, Xiang Shen, Tiefeng Xu, Lei Ying, Jie Sun, Kun Bai, Xianghua Zhang, Jong Heo, Infrared Phys. Technol. 53 (2010) 392-395.

[22] P. Sharma, S. C. Katyal, J.Non-Crystalline. Solids 354 (2008) 3836-3839.

[23] J. Sun, Q. Nie, G. Wang, X. Wang, Acta Physi. Sini. 60 (2011) 114212-114217. 
Tables

\section{Table1}

The physicals, thermal properties of the Ge-Ga-Te-ZnI 2 glass samples and values of bond energy of various possible bonds.

\begin{tabular}{lccccccc}
\hline Sample & $\mathrm{ZnI}_{2} / \mathrm{mol} \%$ & Density $/ \mathrm{g} \cdot \mathrm{cm}^{-3}$ & $\mathrm{~V}_{\mathrm{m}} / \mathrm{cm}^{3} \cdot \mathrm{mol}^{-1}$ & $\mathrm{~T}_{\mathrm{g}}{ }^{\circ} \mathrm{C}$ & $\mathrm{T}_{\mathrm{x}} /{ }^{\circ} \mathrm{C}$ & $\triangle \mathrm{T} /{ }^{\circ} \mathrm{C}$ & $\mathrm{E}_{\mathrm{opt}} / \mathrm{eV}^{\mathrm{a}}$ \\
\hline $\mathrm{T}_{0}$ & 5 & 5.584 & 21.480 & 150 & 227 & 77 & 0.596 \\
$\mathrm{~T}_{1}$ & 10 & 5.600 & 20.874 & 151 & 232 & 82 & 0.610 \\
$\mathrm{~T}_{2}$ & 15 & 5.656 & 20.130 & 152 & 235 & 84 & 0.618 \\
$\mathrm{~T}_{3}$ & 20 & 5.708 & 19.420 & 151 & 241 & 90 & 0.626 \\
\hline Band & & & & & & & \\
Bond & $\mathrm{Ge}-\mathrm{Ge}$ & $\mathrm{Ge}-\mathrm{Te}$ & $\mathrm{Ga}-\mathrm{Te}$ & $\mathrm{Te}-\mathrm{Te}$ & $\mathrm{Ge}-\mathrm{I}$ & $\mathrm{Zn}-\mathrm{Te}$ & $\mathrm{Te}-\mathrm{I}$ \\
energy(kJ/mol) & & & & & & & \\
\hline
\end{tabular}

*a: Indirect optical band gap. 


\section{Figures}

Fig 1. Glass-forming region of $\mathrm{Ge}-\mathrm{Ga}-\mathrm{Te}-\mathrm{ZnI}_{2}$ system.

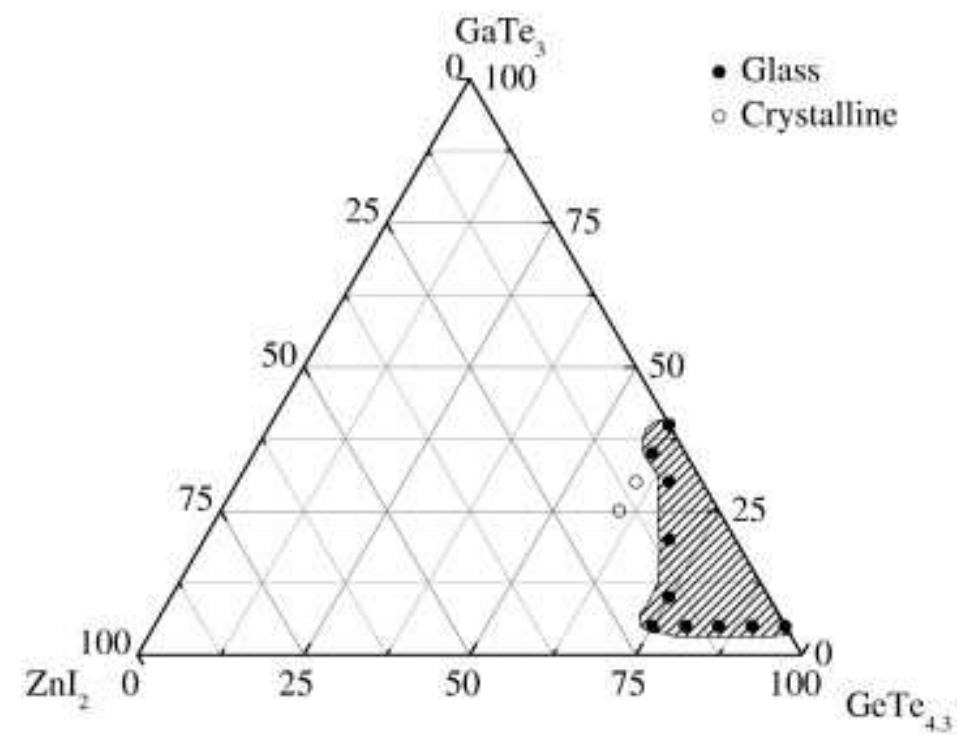

Fig 2. XRD pattern of the powdered glass samples. 


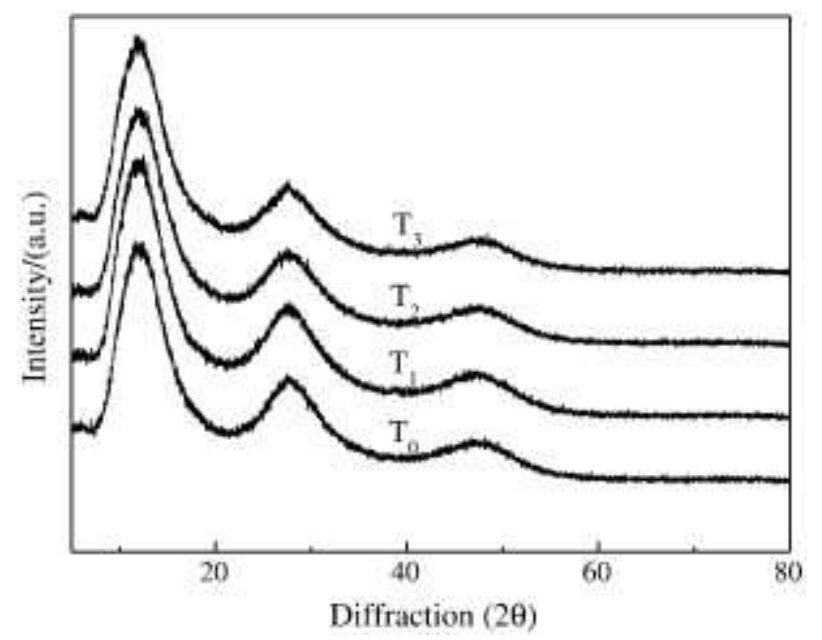

Fig 3. DTA curve of $\mathrm{Ge}-\mathrm{Ga}-\mathrm{Te}-\mathrm{ZnI}_{2}$ glass samples.

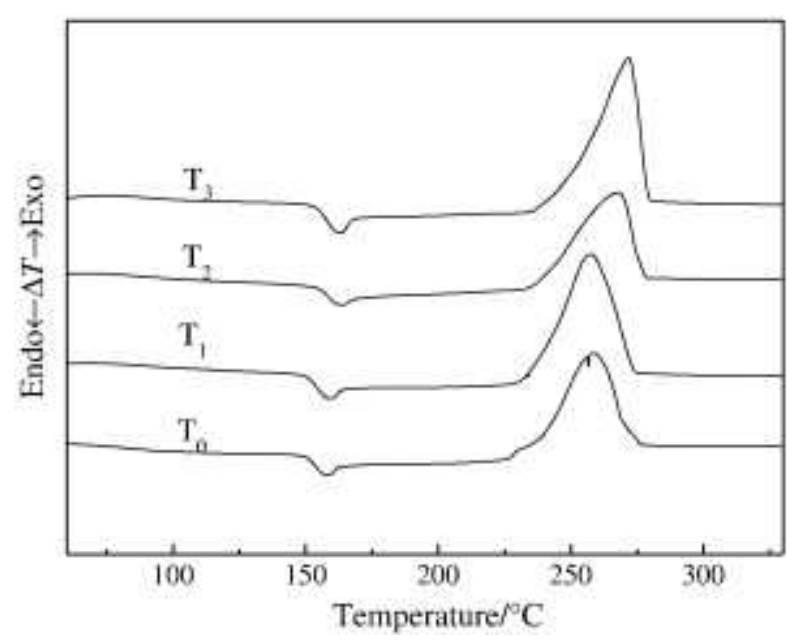

Fig 4. Absorption spectra of glass samples (inset figure is Vis-IR transmission spectra corresponding). 


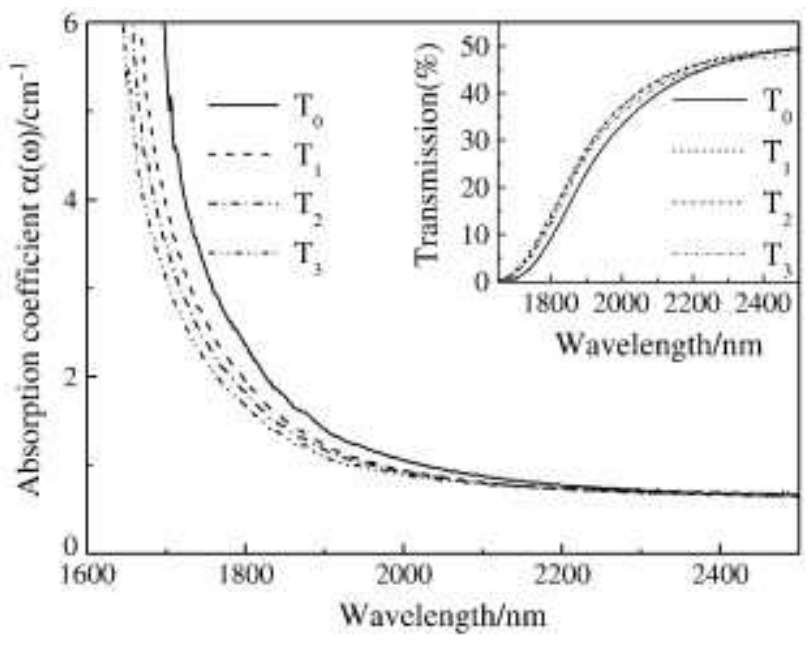

Fig 5. Relationship between $(\alpha h \omega)^{1 / 2}$ and $h \omega$ for glass samples (inset figure is the relationship between indirect optical gap: $E_{\text {opt }}$ and $\mathrm{ZnI}_{2}$ contents).

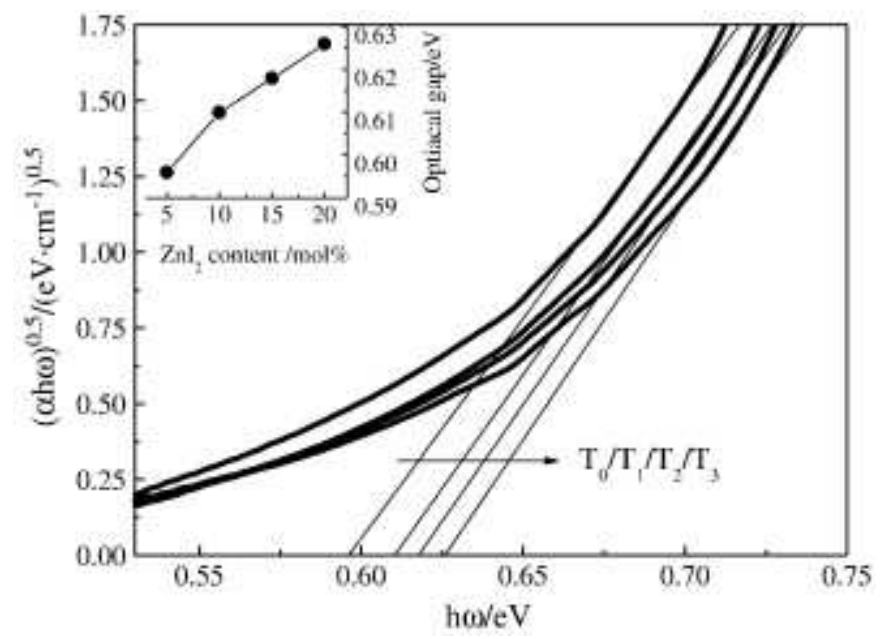

Fig 6. Infrared transmission spectra of $\mathrm{Ge}-\mathrm{Ga}-\mathrm{Te}-\mathrm{ZnI}_{2}$ glass samples. 


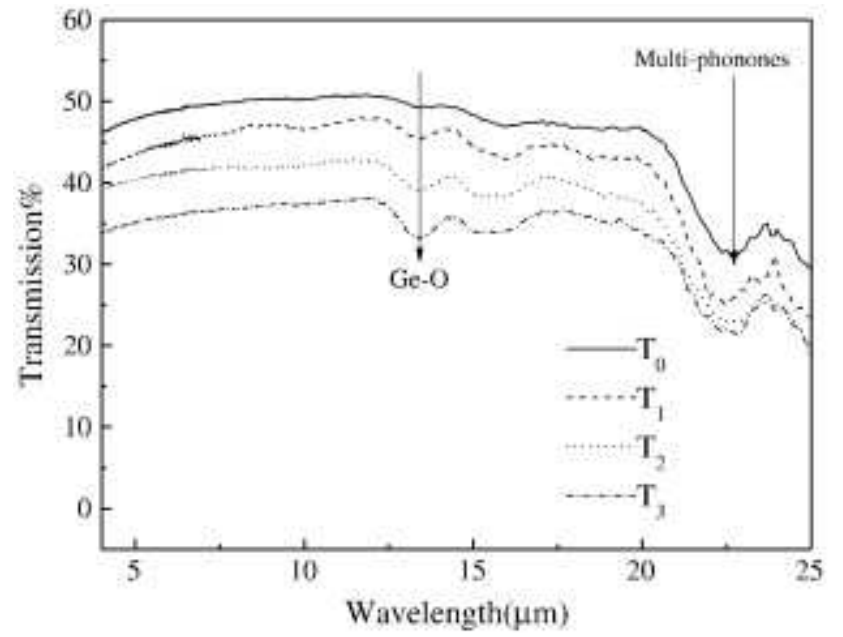

